\title{
Variability of karyotypes and RAPD types in genetically related strains of Cryptococcus neoformans
}

\begin{abstract}
Variation in karyotypes and RAPD patterns of genetically related strains of Cryptococcus neoformans were analyzed. Capsular and filamentous mutants usually differ in their karyotypes from wild-types, but the RAPD patterns were found to be similar. Karyotype differences were observed in most heterothallic matings, but RAPD patterns remained identical. After self-sporulation of a diploid strain, minor chromosomal length polymorphism and minor changes in the RAPD types occurred. Three mechanisms, either alone or in combination, may in varying degrees contribute to the karyotype variation of $C$. neoformans: (1) mitotically induced changes; (2) karyotype changes as a result of meiotic recombination, and (3) mutagen-induced changes. The present data do not support the meiotic maintenance hypothesis, which claims that the amount of CLP generated is inversely proportional to the frequency of meiosis.
\end{abstract}

Key words Cryptococcus neoformans - Karyotype RAPD patterns $\cdot$ Mating $\cdot$ Mutant

\section{Introduction}

Cryptococcus neoformans (Sanfelice) Vuillemin is a prominent medical yeast (Mitchell and Perfect 1995), which is found in nature in the asexual unicellular state. A sexual state can be obtained in vitro by pairing strains of opposite mating type, a or $\alpha$ (Kwon-Chung 1975, 1976, 1978). The usual heterothallic life cycle includes conjugation of haploid yeast cells, which results in dikaryotic hyphae with clamp connections, haustorioid branches, and cylindrical-clavate ba-

\section{T. Boekhout $(\bowtie)$}

Yeast Division, Centraalbureau voor Schimmelcultures,

Julianalaan 67, 2628 BC Delft, The Netherlands

A. van Belkum

Department of Bacteriology, University Hospital Rotterdam,

Rotterdam, The Netherlands

Communicated by K. Wolf sidia. Following meiosis, four basipetal chains of haploid basidiospores are formed (Kwon-Chung 1975, 1976). In addition to the usual haploid cells, diploid yeast cells occur as well (White and Jacobson 1985; Whelan and Kwon-Chung 1986; Takeo et al. 1993). Self-sporulation (or monokaryotic fruiting), resulting in monokaryotic hyphae with incomplete clamp connections, has been reported from diploid strains with mating type $\alpha$ a (Erke 1976; Kwon-Chung 1978; Schmeding et al. 1981 a; Whelan and Kwon-Chung 1986; Takeo et al. 1993), and from haploid wild-type strains with mating type $\alpha$ (Wickes et al. 1996). Additionally, the $\alpha$ a strains may show diploid-haploid mating, in which dikaryotic hyphae with clamp connections and basidia are formed (Schmeding et al. $1981 \mathrm{a}$; T. Boekhout, unpublished observation). Substantial evidence indicates that natural propagation is mainly clonal (Brandt et al. 1995), which is in accordance with the occurrence of geographically restricted populations with similar karyotypes and RAPD patterns (Sorrell et al. 1996a, b; Boekhout et al. 1997).

In epidemiological studies of the species a considerable variation of karyotypes, DNA-fingerprints, and RAPDgenotypes has been demonstrated (Polacheck and Lebens 1989; Perfect et al. 1993; Dromer et al. 1994; Wickes et al. 1994; Brandt et al. 1995, 1996; Varma et al. 1995; Chen et al. 1996). The genetic make-up of the varieties neoformans and gattii was also found to differ from each other (Wickes et al. 1994; Varma et al. 1995; Boekhout et al. 1997). Karyotypes and RAPD patterns usually are stable within strains, but minor variations have been reported as well (Fries et al. 1996; Boekhout et al. 1997). This stability of karyotypes and other genetic markers within strains contrasts with a considerable inter-strain variability.

Given the apparent clonal propagation of the species, the question is how the overall variation of karyotypes and RAPD patterns is generated. We investigated karyotypes and RAPD patterns from the following groups of genetically related isolates: (1) capsular and filamentous mutants (Gordon and Devine 1970; Jacobson and Tingler 1994); (2) heterothallic matings (Kwon-Chung 1978; Schmeding et al. 1981 b); and (3) the self-sporulating strain CBS 7816 with descendants (Schmeding et al. 1981a). 


\section{Materials and methods}

Genetically characterized strains of $C$. neoformans varieties neoformans gattii were obtained from the collections of the Yeast Division of the Centraalbureau voor Schimmelcultures (CBS, Delft, the Netherlands), the American Type Culture Collection (ATCC, Rockville, Maryland, USA), and Dr. E. S. Jacobson (Department of Veterans Affairs, Richmond, Virginia, USA) (Table 1). The identity of the strains was confirmed by testing colour reactions on CGB-medium, D-proline assimilation, serotyping, and killer-toxin sensitivity (Boekhout et al. 1997). Strains were maintained on $1 \%$ yeast extract, $0.5 \%$ peptone, $4 \%$ glucose agar (YPGA) slants at $10^{\circ} \mathrm{C}$.

Table 1 Strains of C. neoformans employed. (Legends: ATCC= American Type Culture collection, Rockville, Maryland, USA; $\mathrm{CBS}=$ Centraalbureau voor Schimmelcultures, Baarn-Delft, The Netherlands; ESJ=E. S. Jacobson, Richmond, Virginia, USA; $\mathrm{NIH}=$ National Institutes of Health, Bethesda, Maryland, USA $\mathrm{RV}=$ Institute of Tropical Medicine, Antwerp, Belgium; UCD =University of California, Davis, California, USA; cap=capsular mutant; $\mathrm{mt}=$ mating type; self $=$ self-sporulating strain; $\mathrm{NTG}=\mathrm{N}$-methyl- $\mathrm{N}^{\prime}$ nitro-N-nitrosoguanidine; UV=ultra-violet)

\begin{tabular}{|c|c|c|}
\hline $\begin{array}{l}\text { CBS } \\
\text { number }\end{array}$ & Other designation & Genetic background \\
\hline 6900 & NIH B-3501 & NIH 430×NIH 12, mt $\alpha$ \\
\hline 6901 & NIH B-3502 & NIH $430 \times$ NIH $12, \mathrm{mt}$ a \\
\hline 7926 & ESJ 59 & cap59-; B-3501, mt $\alpha$, NTG \\
\hline 7927 & ESJ 55 & cap55-; B-3501, mt $\alpha$, NTG \\
\hline 7928 & ESJ 60 & cap60-; B-3501, mt $\alpha, \mathrm{UV}$ \\
\hline 7929 & ESJ 64 & cap64-; B-3501, mt $\alpha$, NTG \\
\hline 7930 & ESJ 66 & cap66-; B-3501, mt $\alpha$, NTG \\
\hline 7931 & ESJ 67 & cap67-; B-3501, mt $\alpha$, NTG \\
\hline 7932 & ESJ 81 & cap81-; B-3502, mt a, UV \\
\hline 7933 & ESJ 195 & cap+; B-3501, mt $\alpha$ \\
\hline 7934 & ESJ 322 & cap55-×B-3502, $\mathrm{mt} \mathrm{a}$ \\
\hline 7935 & ESJ 326 & cap60-×B-3502, $\mathrm{mt} \mathrm{a}$ \\
\hline 7936 & ESJ 328 & cap67-×B-3502, self \\
\hline 7937 & ESJ 331 & cap331-×B-3502, mt $\alpha$ \\
\hline 7938 & ESJ 338 & cap $172 \mathrm{~h} \times \mathrm{B}-3502, \mathrm{mt}$ ? \\
\hline 7816 & ATCC $34868=$ NIH 371 & $\begin{array}{l}\text { Wild, cuckoo droppings, } \\
\text { Thailand, self }\end{array}$ \\
\hline 7823 & ATCC 42163 & Single basidiospore 7816, mt $\alpha$ \\
\hline 7824 & ATCC 42164 & Single basidiospore $7816, \mathrm{mt}$ a \\
\hline 7825 & ATCC 42165 & Single basidiospore 7816 , self \\
\hline 7826 & ATCC 42166 & Single basidiospore 7816 , self \\
\hline 7827 & ATCC 42167 & Single basidiospore 7816 , self \\
\hline 6886 & ATCC $28958=$ NIH 430 & $\begin{array}{l}\text { Wild pigeon droppings, } \\
\text { Denmark, } \mathrm{mt} \text { a }\end{array}$ \\
\hline 7814 & ATCC $32735=$ RV 29192 & Air, Belgium, mt $\alpha$ \\
\hline 7821 & ATCC 42161 & Single basidiospore $6886 \times 7814$ \\
\hline 7822 & ATCC 42162 & Single basidiospore $6886 \times 7814$ \\
\hline 7813 & ATCC $28957=$ NIH 12 & Human bone lesion, $\mathrm{mt} \alpha$ \\
\hline 6901 & ATCC 34874 & Single basidiospore $6886 \times 7813$ \\
\hline 7817 & ATCC 34873 & Single basidiospore $6886 \times 7813$ \\
\hline 7815 & ATCC 34632 & $\begin{array}{l}\text { Pigeon droppings, } \\
\text { Czechoslovakia }\end{array}$ \\
\hline 7000 & ATCC $34875=$ NIH 433 & Pigeon droppings, Denmark \\
\hline 7828 & ATCC 42168 & Single basidiospore $7000 \times 7815$ \\
\hline 7829 & ATCC 42169 & Single basidiospore $7000 \times 7815$ \\
\hline 5728 & UCD $67-57$ & $\begin{array}{l}\text { Non-meningitic cryptococcal } \\
\text { cellulitis and osteomyelitis, USA }\end{array}$ \\
\hline 5729 & UCD 57-68 & Hyphal mutant of 5728 \\
\hline 7812 & ATCC $24064=$ NIH 68 & Cerebrospinal fluid, USA \\
\hline 7820 & & $\begin{array}{l}\text { chemically induced filamentous } \\
\text { mutant of CBS } 7812\end{array}$ \\
\hline 6993 & ATCC $24066=$ NIH 18 & Man, USA \\
\hline 7819 & ATCC 36069 & $\begin{array}{l}\text { Chemically induced filamentous } \\
\text { mutant of } 7819\end{array}$ \\
\hline
\end{tabular}

Pulsed-field gel electrophoresis (PFGE) and randomly amplified polymorphic DNA (RAPD) analysis were performed as described earlier (Boekhout et al. 1997). Densitometric analysis of the karyotypes was performed using a Bio-rad 620 densitometer and 1-D Analyst software (Biorad, Veenendaal, The Netherlands).

\section{Results}

Capsular and filamentous mutants

The sibling strains CBS $6900(=\mathrm{NIH}$ B-3501) and CBS 6901 (=NIH B-3502) (Kwon-Chung 1978) showed some chromosomal length polymorphism (CLP) (Fig. 1 B, arrow heads). Karyotype variation was also found among UVor N-methyl-N'-nitro-N-nitrosoguanidine (NTG)-induced capsular mutants of these two siblings (Jacobson and Tingler 1994) (Fig. 1, arrow heads), although the difference concerned only one or two bands. The second (approximately $2.2 \mathrm{Mb}$ ) and third (approximately $1.8 \mathrm{Mb}$ ) band from the top were most frequently affected by the mutagen. The mutant strains CBS 7926 (cap59-), CBS 7929 (cap64-), and CBS 7983 (cap+) differed from the parental strain NIH B-3501 by the absence of an approximately $1.8 \mathrm{Mb}$ chromosome, CBS 7930 (cap66-) lacked an approximately $2.2 \mathrm{Mb}$-sized chromosome, and the NTG-mutant CBS 7927 (cap55-) possessed an additional chromosome of approximately $1.6 \mathrm{Mb}$ (Fig. 1, arrow heads). The karyotypes of CBS 7928 (cap60-) and CBS 7931 (cap67-) were identical with the wild-type. The karyotype of CBS 7932, a UV-induced mutant of NIH B-3502, differed from its wild-type by the presence of a somewhat larger third chromosome of approximately $2 \mathrm{Mb}$ (Fig. 1 A, arrow head).

Chromosomes 1 and 4-11, according to the numbering of Wickes et al. (1994), were found to be stable after these mutagenic treatments. Crossings between some of the capsular mutants with NIH B-3502 (=CBS 6901), a sibling of the originally used wild-type strain NIH B-3501 (=CBS 6900) (Jacobson and Tingler 1994), may also cause changes in the karyotype (Fig. 1 B). In most cases, karyotypes of the $\mathrm{F}_{1}$ generation strains were identical with or similar to those of the $\mathrm{F}_{0}$ generation, or else possessed a hybrid pattern. CBS 7934 (cap55-×NIH B-3502), however, lacked an approximately 0.9-Mb-sized chromosome (Fig. 1B).

Karyotype differences were also observed when wildtype isolates CBS 5728 and CBS 7812 and their respective filamentous mutants CBS 5729 and CBS 7820 were compared (Fig. 2B). However, the karyotype of the filamentous mutant CBS 7819 was found to be identical with its wild-type strain CBS 6993 (data not shown). The RAPD patterns of the mutant strains were identical with those of the wild-types (data not shown).

\section{Heterothallism}

Karyotype changes were usually observed following mating (Fig. 2 A, B), and comprised both inter- and intra-chro- 


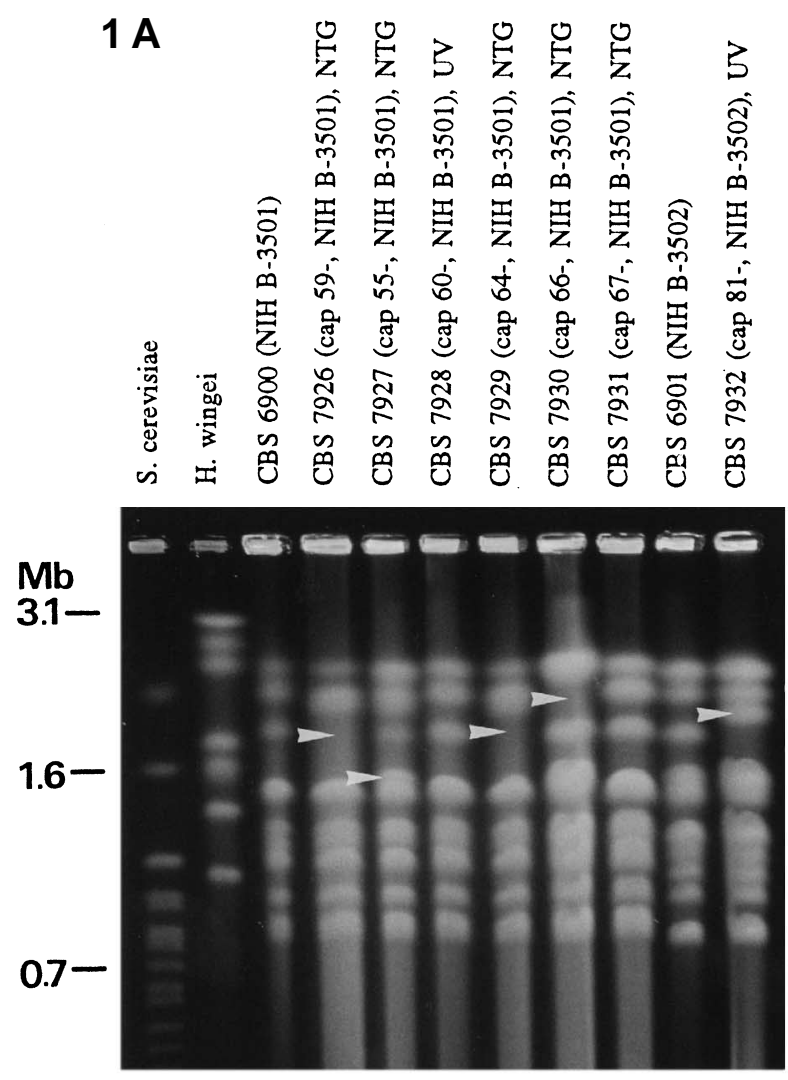

$1 B$

$2 \mathrm{~A}$

2B
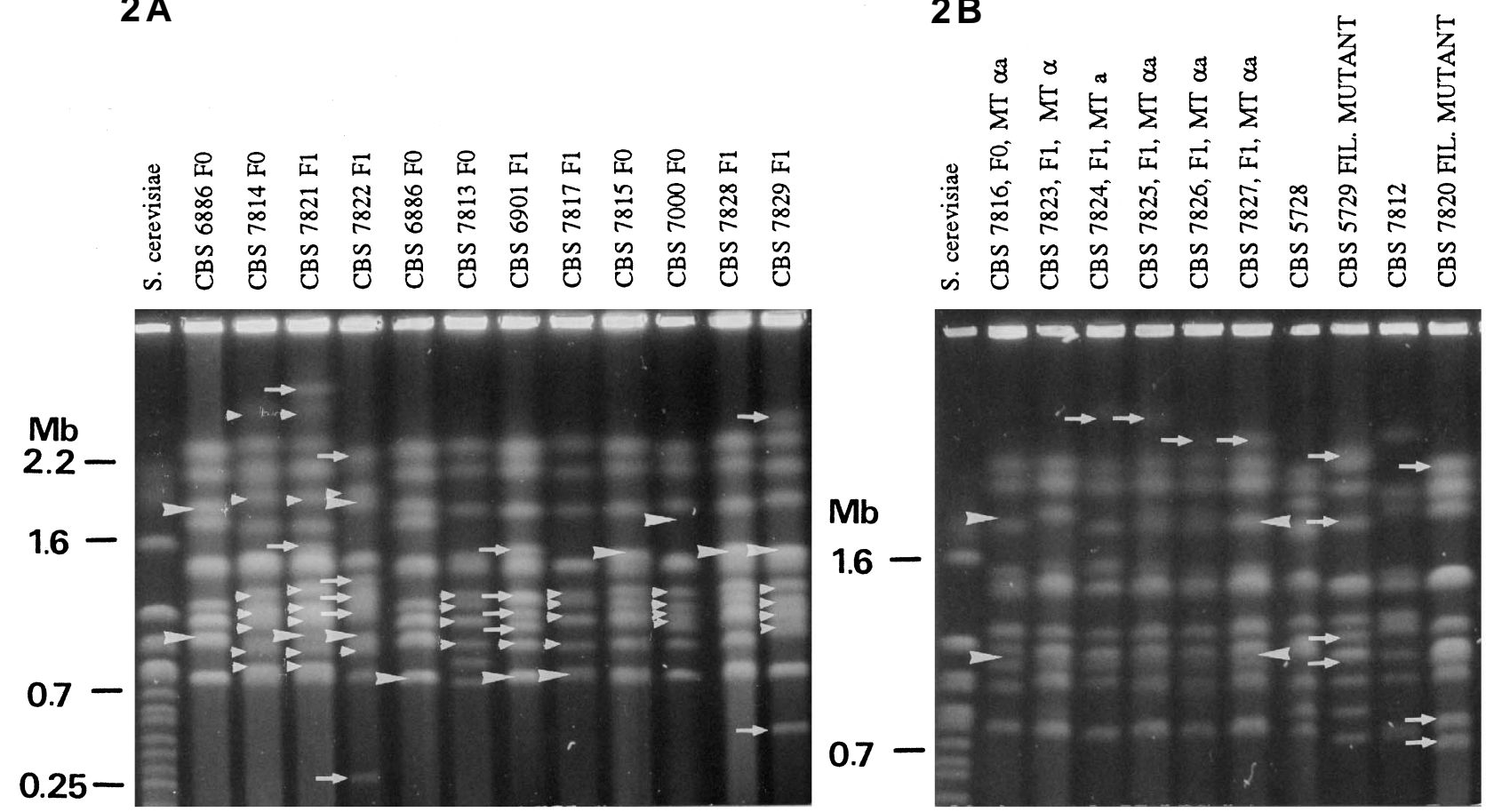

Fig. 1A, B Karyotypes of capsular mutants of C. neoformans (for explanation of symbols see Table 1; arrow heads indicate the most significant changes in the karyotypes)

Fig. 2A, B Karyotypes of heterothallic (panel $A$ ), self-sporulating and filamentous mutant strains (panel $B$ ) of $C$. neoformans (for explanation of symbols see Table 1; novel bands are indicated with arrows, and bands occurring in one of the parental strains are indicated by small and large arrow heads, respectively. In panel $B$ chromosomes with CLP are indicated with a large arrow head) 


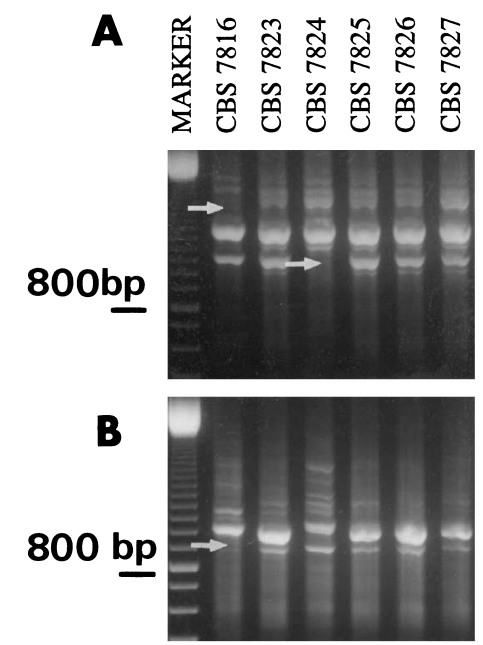

Fig. 3A, B RAPD pattern of the self-sporulating strain strain CBS 7816 and some of its $\mathrm{F}_{1}$ offspring using ERIC1 (panel $A$ ) and ERIC2 (panel $B$ ) primers (arrows indicate changes in the RAPD types)

mosomal rearrangements, resulting in chromosomal length polymorphism (CLP). Intra-chromosomal changes included size variations, and rearrangements of partial or entire chromosomes were interpreted as inter-chromosomal changes.

The karyotype of CBS 7821, a $\mathrm{F}_{1}$-generation isolate of the mating between CBS 7814 and 6886, had many bands in common with its parent strain CBS 7814 (small arrow heads). One band was obtained from the other parent strain (large arrow head), few bands occurred in both parents, and two unique bands of approximately 1.5 and $>2.2 \mathrm{Mb}$ sizes were present (arrows). The RAPD pattern of CBS 7821 was identical with that of CBS 7814. The karyotype of the sibling strain CBS 7822 (CBS $7814 \times$ CBS 6886) also possessed a hybrid pattern. Novel chromosomes of approximately 0.3 and $2.2 \mathrm{Mb}$ were present, and the three chromosomes of approximately 1.0 Mb showed CLP (arrows). Two chromosomes of approximately 1.0 and $2.0 \mathrm{Mb}$ were obtained from CBS 6886 (large arrow heads), and another of $\leq 2.0$ and approximately $1.0 \mathrm{Mb}$ were present in the other parent (small arrow heads). The RAPD pattern of CBS 7822 was similar to that of the parental strain CBS 6886.

The mating CBS $6886 \times$ CBS 7813 also resulted in karyotype changes (Fig. 2A). CBS 6901 possessed a unique band of approximately $1.6 \mathrm{Mb}$, and a series of bands of approximately $1.0 \mathrm{Mb}$ showed CLP (arrows). The karyotype of the sibling strain CBS 7817 largely agreed with that of the parent strain CBS 7813 (small arrow heads), but the lowermost band occurred in parent strain CBS 6886 (large arrow head). The RAPD patterns of all these isolates were identical.

The karyotype of CBS 7828, a $\mathrm{F}_{1}$-generation isolate from the mating CBS $7815 \times$ CBS 7000 , was identical with that of parent strain CBS 7815. Its sibling CBS 7829, however, had a hybrid pattern with one band obtained from the parent CBS 7815 (large arrow head), four from CBS 7000 (small arrow heads), and two unique chromosomes occurred of >2.2 Mb and approximately $0.5 \mathrm{Mb}$ (arrows).

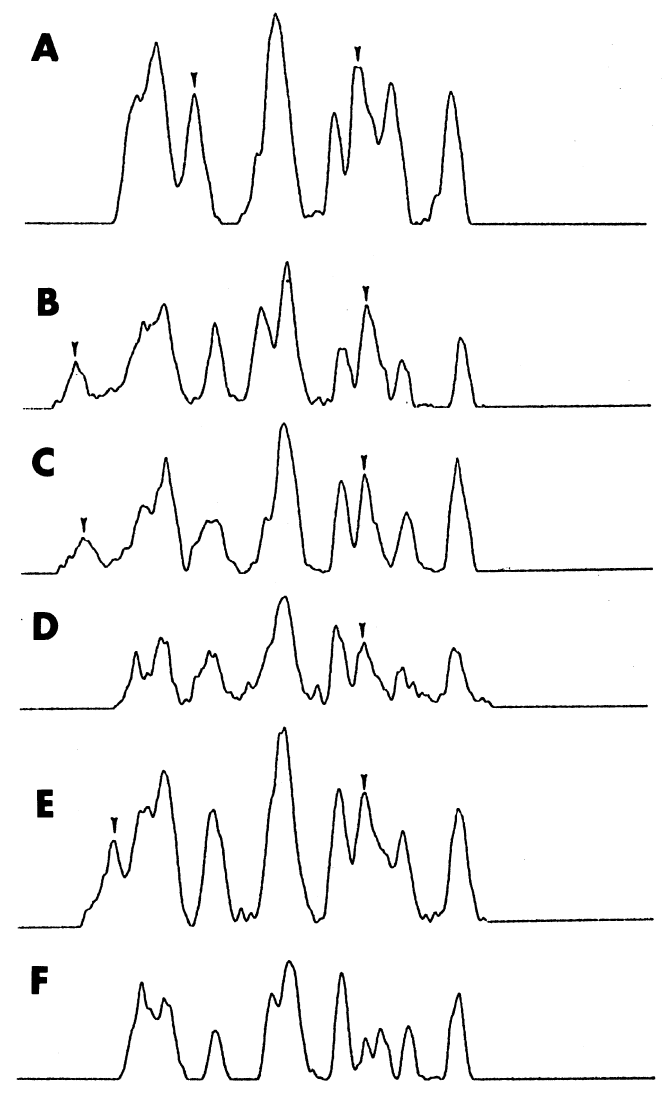

Fig. 4A-F Densitometric tracings of karyotypes of the self-sporulating strain CBS 7816 and some of its $\mathrm{F}_{1}$ offspring. A CBS 7873, $\mathrm{F}_{1}$, mt $\alpha$; B CBS 7824, $\mathrm{F}_{1}$, mt a; C CBS 7825, $\mathrm{F}_{1}$, mt $\alpha$ a ; 7826, $\mathrm{F}_{1}$, mt $\alpha \mathrm{a} ; \mathbf{E} 7827, \mathrm{~F}_{1}$, mt $\alpha \mathrm{a} ; \mathbf{F}$ CBS 7816, $\mathrm{F}_{0}$, mt $\alpha \mathrm{a}$. Arrows indicate novel chromosomes or altered densities

The RAPD patterns of these $F_{0}$ and $F_{1}$ generation strains were found to be identical.

\section{Self-sporulation}

Karyotypes of the $\mathrm{F}_{1}$ generation isolates obtained from the self-sporulating strain CBS 7816 had nine bands in common with the parent strain (Fig. 2B). CLP was observed in the third band from the top (approximately $1.8 \mathrm{Mb}$ ), and in the two chromosomes of approximately $1.0 \mathrm{Mb}$ (Fig. 2B large arrow heads; Fig. 4). Some $\mathrm{F}_{1}$-strains, namely CBS 7824, 7825, 7826 and 7827, showed an additional large chromosome of $>2.2 \mathrm{Mb}$ (arrows). RAPD patterns of the $F_{0}$ and $F_{1}$ generations were rather similar, with the exception of the $F_{1}$ generation strain CBS 7824, which showed a somewhat different banding pattern with primers ERIC1 and ERIC2 (Fig. 3).

The largest chromosomes $(\geq 2.2 \mathrm{Mb})$ were most frequently involved in karyotype modifications following heterothallic mating and self-sporulation. The chromosomes of approximately $2.2 \mathrm{Mb}$ (chromosomes 1 and 2 of Wickes et al. 1994), approximately $1.5 \mathrm{Mb}$ (chromosomes 4-6 of Wickes et al. 1994), and 0.7 Mb (chromosome 12 of Wickes et al. 1994) were relatively stable. 


\section{Discussion}

Chromosome-length polymorphism (CLP) occurs in many species of yeasts and filamentous fungi (Zolan 1995), and this feature may be useful in epidemiological studies of plant-, animal- and human-pathogens (e.g. Cooley and Caten 1991; Perfect et al. 1993; Dromer et al. 1994). Our results indicate that karyotypes are more prone to variation than RAPD-types. A different RAPD pattern is usually reflected in a different karyotype, but differences in karyotypes do not always coincide with RAPD differences.

A better understanding of the mechanism of karyotype diversification in $C$. neoformans may be relevant to the analysis of variations observed in epidemiological studies (Fries et al. 1996; Boekhout et al. 1997), and to fungal genetics in general. An interesting paradox has been observed in $C$. neoformans, as well as in many other species, namely mitotic stability of karyotypes, i.e. low levels or absence of intra-strain variability, together with a considerable inter-strain variability (Perfect et al. 1993; Mitchell and Perfect 1995; Zolan 1995; Boekhout et al. 1997). Karyotypes of many species studied do not change during mitosis (Boekhout et al. 1991 a; Cooley and Caten 1991; Russell and Mills 1993; Talbot et al. 1993; Boehm et al. 1994), whereas meiosis usually results in changes of karyotypes (Ono and Ishino-Arao 1988; Plummer and Howlett 1993; Zolan et al. 1994; Martin 1995). The present and earlier studies (Perfect et al. 1993) suggested that karyotypes of C. neoformans are relatively stable mitotically, but that they can change considerably during meiosis. However, minor karyotype changes have been observed in a number of sequential isolates from one patient, and also after experimental infection of mice (Fries et al. 1996; Boekhout et al. 1997).

The observed combination of inter-strain variability, mitotic stability and meiotic instability of karyotypes in C. neoformans is not easy to explain. Linkage disequilibrium studies suggested that $C$. neoformans mainly propagates clonally (Brandt et al. 1995). If this is true, it seems unlikely that meiotic recombination contributes significantly to the observed inter-strain variability in nature.

Initially we did not conceive a major role for mitotic recombination in the process of generating karyotype variation in $C$. neoformans. However, an accumulation of small chromosomal changes may alter karyotypes after many generations (Zolan 1995). A number of observations support the occurrence of mitotic changes of karyotypes in C. neoformans: (1) CLP of the largest chromosome was observed in the $C$. neoformans var. gattii when using different storage regimes (Boekhout et al. 1997); (2) minor karyotype differences were observed in multiple isolates from a patient, as well as after passage through mice with clinical and saprobic isolates (Fries et al. 1996; Boekhout et al. 1997); (3) chromosome variation of $C$. neoformans was found to be induced by mutagenic treatments. Rapid mitotic change of karyotypes, as occurs in some asexual yeasts, e.g. Candida albicans (Rustchenko-Bulgac and Howard 1993), does not occur in C. neoformans. Karyo- type changes, as seen in the hyphal mutants of $C$. neoformans, have also been observed after yeast-hyphal transitions in other species (Boekhout et al. 1991 b; McEachern and Hicks 1991), and after transformation experiments (Xuei and Skatrud 1994).

Karyotype variation of $C$. neoformans clearly increased after meiosis. Most of the chromosomes of the $F_{1}$ progeny could be traced to one or both of the parental strains using band size as a parameter. Several chromosomes were transferred without apparent length changes, whereas others showed length variation. Reciprocal recombination between homologous chromosomes of unequal size was suggested as an explanation of karyotype variation in Leptosphaeria maculans (Plummer and Howlett 1993, 1995). This model may also explain the occurrence of chromosomal reorganization after meiotic recombination in $C$. neoformans. The importance of this observation for the biology of the species is not clear, as sexual reproduction of the species has not yet been observed in nature. However, the occurrence of genetic recombination among populations of $C$. neoformans in nature cannot be ruled out completely, as was shown recently also for the asexual fungus Coccidioides immitis (Burt et al. 1996), and deserves further study.

C. neoformans possesses a number of alternative sexual strategies, such as heterothallism, self-sporulation of haploid and diploid isolates, and mono-dikaryotic matings (Kwon-Chung 1978; Schmeding et al. $1981 \mathrm{a}$, b; Takeo et al. 1993; Wickes et al. 1996), which may affect the chromosomal make-up in various ways. The importance of these different sexual strategies is not yet clear, as they have thus far been observed only in the laboratory. Selfsporulation of a diploid strain of $C$. neoformans resulted in relatively minor intra-chromosomal changes, whereas more extensive changes occurred following heterothallic matings. This suggests that different mechanisms of chromosomal transfer operate during self-sporulation and heterothallism. Mutagen-sensitive sites may be unequally distributed among the genome, as certain chromosomes of C. neoformans were found to be more sensitive to mutagenic treatment than others. Karyotype variation in $C$. neoformans appears to be genetically neutral as thus far no obvious correlation has been observed with any beneficial phenotypic changes. RAPD patterns were usually not altered after meiotic recombination or mutagenic treatments, but minor changes occurred in the RAPD patterns of $F_{1}$ isolates following self-sporulation.

Our results on $C$. neoformans (see also Boekhout et al. 1997) do not support the meiotic-maintenance hypothesis, which claims that the amount and extent of karyotype variation is inversely related with the frequency of meiosis (Kistler and Miao 1992). According to our present knowledge, three independently acting mechanisms may contribute in different degrees to the observed karyotype variation in $C$. neoformans: (1) mitotically induced changes; (2) mutageninduced changes; and (3) meiotically induced changes. Further studies are required to analyze the relative importance of these three alternatives for the genetic make-up of the species, either in nature and in the laboratory. More detailed in- 
sight into the micro-evolution of the genome of $C$. neoformans will contribute to our understanding of the population genetics and adaptation to the human host of this species.

Acknowledgements The authors are grateful to Dr. E. S. Jacobson (Richmond, Virginia, USA) for providing the capsular mutant strains.

\section{References}

Boehm EWA, Ploetz RC, Kistler HC (1994) Statistical analysis of electrophoretic karyotype variation among vegetative compatibility groups of Fusarium oxysporum f. sp. cubense. Mol PlantMicrobe Interact 7:196-207

Boekhout T, Gool J van, Boogert H van den, Jille T (1991 a) Karyotyping and $\mathrm{G}+\mathrm{C}$ composition as taxonomic criteria applied to the systematics of Tilletiopsis and related taxa. Mycol Res 95:331-342

Boekhout T, Poot G, Hackman P, Steensma HY (1991 b) Genomic characteristics of strains of Itersonilia: taxonomic consequences and life cycle. Can J Microbiol 37: 188-194

Boekhout T, Belkum A van, Leenders ACAP, Verbrugh HA, Mukamurangwa P, Swinne D, Scheffers WA (1997) Molecular typing of Cryptococcus neoformans: taxonomic and epidemiological aspects. Int J Syst Bact 47:432-442

Brandt ME, Hutwagner LC, Kuykendall RJ, Pinner RW, Cryptococcal Disease Active Surveillance Group (1995) Comparison of multilocus enzyme electrophoresis and random amplified polymorphic DNA analysis for molecular subtyping of Cryptococcus neoformans. J Clin Microbiol 33: 1890-1895

Brandt ME, Hutwagner LC, Klug LA, Baughman WS, Rimland D, Graviss EA, Hamill RJ, Thomas C, Pappas PG, Reingold AL, Pinner RW, Cryptococcal Disease Active Surveillance Group (1996) Molecular subtype distribution of Cryptococcus neoformans in four areas of the United States. J Clin Microbiol 34:912-917

Burt A, Carter DA, Koenig GL, White TJ, Taylor JW (1996) Molecular markers reveal cryptic sex in the human pathogen Coccidioides immitis. Proc Natl Acad Sci USA 93:770-773

Chen SCA, Brownlee AG, Sorrell TC, Ruma P, Ellis DH, Pfeiffer T, Speed BR, Nimmo G (1996) Identification by random amplification of polymorphic DNA of a common molecular type of Cryptococcus neoformans var. neoformans in patients with AIDS or other immunosuppressive conditions. J Inf Dis 173:754-758

Cooley RN, Caten CE (1991) Variation in electrophoretic karyotype between strains of Septoria nodorum. Mol Gen Genet 228: 17-23

Dromer F, Varma A, Ronin O, Mathoulin S, Dupont B (1994) Molecular typing of Cryptococcus neoformans serotype D clinical isolates. J Clin Microbiol 32:2364-2371

Erke KH (1976) Light microscopy of basidia, basidiospores, and nuclei of spores and hyphae of Filobasidiella neoformans (Cryptococcus neoformans). J Bacteriol 128:445-455

Fries BC, Chen F, Currie BP, Casadevall A (1996) Karyotype instability in Cryptococcus neoformans infection. J Clin Microbiol 34: 1531-1534

Gordon MA, Devine J (1970) Filamentation and endogenous sporulation in Cryptococcus neoformans. Sabouraudia 8:227-234

Jacobson ES, Tingler MJ (1994) Strains of Cryptococcus neoformans with defined capsular phenotypes. J Med Vet Mycol 32:401-404

Kistler HC, Miao VPW (1992) New modes of genetic change in filamentous fungi. Annu Rev Phytopathol 30:131-152

Kwon-Chung KJ (1975) A new genus Filobasidiella, the perfect state of Cryptococcus neoformans. Mycologia 67: 1197-1200

Kwon-Chung KJ (1976) A new species of Filobasidiella, the sexual state of Cryptococcus neoformans B and C serotypes. Mycologia 68:942-946

Kwon-Chung KJ (1978) Heterothallium vs self-fertile isolates of Filobasidiella neoformans (Cryptococcus neoformans). Proc IV Int Conf Mycoses, pp 204-213

Martin F (1995) Meiotic instability of Pythium sylvaticum as demonstrated by inheritance of nuclear markers and karyotype analysis. Genetics 139: 1233-1246
McEachern MJ, Hicks JB (1991) Dosage of the smallest chromosome effects both the yeast-hyphal transition and the whiteopaque transition of Candida albicans WO-I. J Bacteriol 173:7436-7442

Mitchell TG, Perfect JR (1995) Cryptococcosis in the era of AIDS - 100 years after the discovery of Cryptococcus neoformans. Clin Microbiol Rev 8:515-548

Ono B, Ishino-Arao Y (1988) Inheritance of chromosome length polymorphism in Saccharomyces cerevisiae. Curr Genet 14:413-418

Perfect JR, Ketabchi N, Cox GM, Ingram CW, Beiser CL (1993) Karyotyping of Cryptococcus neoformans as an epidemiological tool. J Clin Microbiol 31:3305-3309

Plummer KM, Howlett BJ (1993) Major chromosomal length polymorphisms are evident after meiosis in the phytopathogenic fungus Leptosphaeria maculans. Curr Genet 24: 107-113

Plummer KM, Howlett BJ (1995) Inheritance of chromosomal length polymorphisms in the ascomycete Leptosphaeria maculans. Mol Gen Genet 247:416-422

Polacheck I, Lebens GA (1989) Electrophoretic karyotype of the pathogenic yeast Cryptococcus neoformans. J Gen Microbiol 135:65-71

Russell BW, Mills D (1993) Electrophoretic karyotypes of Tilletia caries, $T$. controvers $a$, and their $\mathrm{F}_{1}$ progeny: further evidence for conspecific status. Mol Plant-Microbe Interact 6:66-74

Rustchenko-Bulgac EP, Howard DH (1993) Multiple chromosomal and phenotypic changes in spontaneous mutants of Candida albicans. J Gen Microbiol 139: 1195-1207

Schmeding KA, Jong SC, Hugh R (1981a) Monokaryotic fruiting and its sexuality in self-fertile strains of Filobasidiella neoformans (Cryptococcus neoformans). Trans Mycol Soc Japan 22: $1-10$

Schmeding KA, Jong SC, Hugh R (1981 b) Sexual compatability between serotypes of Filobasidiella neoformans (Cryptococcus neoformans). Curr Microbiol 5: 133-138

Sorrell TC, Chen SCA, Ruma P, Meyer W, Pfeiffer TJ, Ellis DH, Brownlee AG (1996a) Concordance of clinical and environmental isolates of Cryptococcus neoformans var. gattii by random amplification of polymorphic DNA analysis and PCR fingerprinting. J Clin Microbiol 34: 1253-1260

Sorrell TC, Brownlee AG, Ruma P, Malik R, Pfeiffer TJ, Ellis DH (1996b) Natural environmental sources of Cryptococcus neoformans var. gattii. J Clin Microbiol 34: 1262-1263

Takeo K, Tanaka R, Taguchi H, Nishimura K (1993) Analysis of ploidy and sexual characteristics of natural isolates of Cryptococcus neoformans. Can J Microbiol 39:958-963

Talbot NJ, Salch YP, Ma M, Hamer JE (1993) Karyotypic variation within clonal lineages of the rice blast fungus, Magnaporthe grisea. Appl Envir Microbiol 59:585-593

Varma A, Swinne D, Bennett JE, Kwon-Chung KJ (1995) Diversity of DNA fingerprints in Cryptococcus neoformans. J Clin Microbiol 33:1807-1814

Whelan WL, Kwon-Chung KJ (1986) Genetic complementation in Cryptococcus neoformans. J Bacteriol 166:924-929

White CW, Jacobson ES (1985) Occurrence of diploid strains of Cryptococcus neoformans. J Bacteriol 161: 1231-1232

Wickes BL, Moore TDE, Kwon-Chung KJ (1994) Comparison of the electrophoretic karyotypes and chromosomal location of ten genes in the two varieties of Cryptococcus neoformans. Microbiology 140:543-550

Wickes BL, Mayorga ME, Edman U, Edman JC (1996) Dimorphism and haploid fruiting in Cryptococcus neoformans: association with the $\alpha$-mating type. Proc Natl Acad Sci USA 93:7327-7331

Xuei X, Skatrud PL (1994) Molecular karyotype alterations induced by transformation in Aspergillus nidulans are mitotically stable. Curr Genet 26:225-227

Zolan ME (1995) Chromosome-length polymorphism in fungi. Microbiol Rev 59:686-698

Zolan ME, Heyler NK, Stassen NY (1994) Inheritance of chromosome-length polymorphisms in Coprinus cinereus. Genetics 137:87-94 